\title{
Base Nacional Comum Curricular: apontamentos crítico-clínicos e um trampolim
}

\author{
Common National Curricular Base: critical-clinical notes and a trampoline
}

Base Nacional Común Curricular: apuntamientos crítico-clínicos y un trampolín

SANDRA MARA CORAZZA*

\begin{abstract}
$\longrightarrow \diamond$
RESUMO

Este artigo realiza o esforço de constituir movimentos de análise crítica e de interlocução clínica, no espaço-tempo da Base Nacional Comum Curricular, tal como esta foi exposta em primeira versão destinada à consulta pública (20152016). Movimentos críticos-clínicos, que parecem necessários para acompanhar os enigmáticos deslocamentos e rearranjos, pelos quais passam o país, o mundo, o capital, o trabalho, as relações, a educação. Por meio de uma analítica genealógico-nietzschiana, problematiza o quadrilátero conceitual-operatório da Base; releva suas figuras e o artifício fabulatório que lhe dá sustentação; indica 16 questionamentos a seus elementos constituintes. Conclui pela proposição de pensar e sentir a Base Nacional Comum Curricular, como abertura democrática para a formulação de novos problemas antes do que soluções e como um trampolim para currículos que emerjam do dia-a-dia da docência, levando os professores a se tornarem, outra vez, os seus autores.
\end{abstract}

Palavras-chave: Base Nacional Curricular.

\begin{abstract}
This article aims to constitute the critical analysis and clinical interlocution movements, in the time-space of the Common National Curricular Base, which has been exposed as a first version to public query (2015-2016). Criticalclinical movements, which seems necessary to keep up with the enigmatic displacements and rearrangements, from whose the country, the world, the capital, the work, the relations and the education are going through. Through an nietzschean-genealogic analysis, it problematizes the conceptual-operatory quadrilateral of the Base; reveal it's figures and the fable making artifice that gives it foundation; it indicates sixteen questions to it's constituents elements. Concludes by the preposition of thinking and feeling the Common National Curricular Base, as an democratic opening for the (formulation) of new problems before new solutions and as an trampoline for the curriculums that emerge from every-day teaching, leading teacher to become, once again, the authors.
\end{abstract}

Keywords: National Curricular Base

\begin{abstract}
RESUMEN
Este artículo realiza el esfuerzo de constituir movimientos de análisis crítica y de interlocución clínica, en el espaciotiempo de la Base Nacional Común Curricular, a la manera como esta fue expuesta en la primer versión con destino a la consulta pública (2015-2016). Movimientos críticos-clínicos, que parecen necesarios para acompañar los enigmáticos desplazamientos y reordenamiento, por los cuales pasan el país, el mundo, el capital, el trabajo, las relaciones, la educación. Por medio de una analítica genealógico-nietzschiana, problematizar el cuadrilátero conceptual-operatorio de la Base; revela sus figuras y el artificio fabulatorio que le da sustento; indica 16 cuestionamientos a sus elementos constituyentes. Concluye por la proposición de pensar y sentir la Base Nacional Común Curricular, como apertura democrática para la formulación de nuevos problemas antes de que soluciones y como un trampolín para currículos que emerjan del día a día de la docencia, llevando los profesores a tornarense, otra vez, sus autores.
\end{abstract}

Palabras clave: Base Nacional Curricular.

\footnotetext{
* Professora Titular da Faculdade de Educação da Universidade Federal do Rio Grande do Sul. Pesquisadora de Produtividade do CNPq. E-mail: <sandracorazza@terra.com.br>.
} 


\section{SINTOMA SOCIAL E DEMOCRACIA}

Este artigo realiza o esforço de constituir movimentos de análise crítica e de interlocução clínica, no espaçotempo da Base Nacional Comum Curricular (20152016), tal como esta foi exposta em primeira versão destinada à consulta pública (http://basenacionalcomum. mec.gov.br/). Movimentos críticos-clínicos que nos parecem necessários para acompanhar os enigmáticos deslocamentos e rearranjos, pelos quais passam o país, o mundo, o capital, o trabalho, as relações, a educação - e nós, professores, no meio desses movimentos: atônitos, intrigados, preocupados e, muitas vezes, perdidos.

Assim participando, damos prosseguimento ao trabalho em prol da democracia, embora reconheçamos a dificuldade do seu exercício; a não assunção de sua possibilidade plena; e a sua constante necessidade de melhorias. Almejamos a democracia, pois sabemos que, somente por meio dela, conseguimos circular nos caminhos das palavras recalcadas. Aquelas palavras que, como as ditaduras tão cruamente inscreveram em nossos corpos, estão vinculadas à violência e à dor - desde que, em outro funcionamento, que não o democrático, não se fala o que dói e a violência silencia (Rodriguez; Berlink, 1988).

Por isso, as palavras silenciadas manifestam-se como sintomas sociais, tais como as forças secundárias de adaptação e regulação; o golpismo, o lucro, o poder e a vaidade; a repressão policial e a proteção ao tráfico de drogas e de pessoas; as formas inusitadas de controle social e subjetivo; os retrocessos nas conquistas sociais; o retorno ao misticismo, culto ao natural e todos os neoarcaísmos; alianças políticas espúrias e corrupção privada do dinheiro público; a miséria, a morte e o horror - isto é, tudo aquilo que diminui e avilta a vida.

Sintoma social, como um conceito, formulado no primeiro tomo do Capital, o qual consiste, para Marx (2008), na manifestação de um estado patológico do socius, que conduz a rupturas e suspensões no curso de um modo de produção. Tal como uma necessidade, a princípio, lógica, do funcionamento do discurso capitalista, os acontecimentos, interpretados como sintomas sociais, são metáforas de algo impossível de ser dito, como causalidade não contingencial, efeito de estrutura ou de real. Também Freud (1981a; b), nos textos O futuro de uma ilusão e em Mal-estar na civilização, concebe o sintoma social como efeito de uma legalidade não apreensível diretamente, sendo expressão de algo que fica além de um desajuste corrigível.

Embora não estejamos falando, aqui, de um terrorismo de Estado, como o mais mortífero dos instrumentos que conhecemos, importa indagar se não estaremos vivendo, hoje, no Brasil, em relação às palavras crítico-clínicas, um terror de tipo segmentarizado. Por efeitos dos novos sintomas sociais, não estamos sofrendo de anomia, alienação, desintegração, indefinições, não persistência, busca de facilidades, incapacidade de estabelecer laços, insegurança em relação à sobrevivência, fascínio pela megamáquina capitalística e planetária, nihilismo absoluto, cínico e egoísta?

Será que um dos sintomas sociais, próprio aos professores, na atualidade, não consiste em delegar responsabilidades, que seriam específicas da práxis docente e da pesquisa educacional, a algo, alguma instituição ou alguém, como: igrejas, templos, pastores, comitês de ética, poder executivo, conselhos universitários, ministérios, editoras, reitorias, direções, colegiados, chefias, secretarias, líderes carismáticos ou de plantão?

Será que não reduzimos ou, mesmo, abandonamos o nosso compromisso ético com a herança dos que nos antecederam, dos tempos que nos tocaram viver e trabalhar, e com a resolução dos problemas educacionais? O que estamos fazendo, por exemplo, pela indisciplina, desinteresse e violência nas escolas; pelos ativismos sindicais e abstenções nas universidades; pelos saberes totalitários e raivas dogmáticas?

Não seria o caso de agora, outra vez, diante da Base Nacional Comum Curricular, retomar, verter e reverter as lutas que somente a nós competem, nos campos do currículo e da didática, para assegurar a cada professor o caráter autoral de sua profissão e a liberdade criadora de suas palavras livres? Para isso, talvez, necessitemos, entre outras reinvenções - como as das formas de luta e do exercício do poder institucional -, de dispositivos favoráveis, que transformem as falhas da democracia, que ajudamos a criar, em lugares de auto-interrogação e de problematizações.

Nessa direção, discutir, critica e clinicamente, a Base Nacional parece consistir em um potente dispositivo democrático, pelo qual somos todos responsáveis, tanto junto ao Ministério da Educação, como ao lado de colegas que, ao longo do tempo, participaram da sua elaboração, pelo muito do seu trabalho e também do nosso (como comunidade educacional), que ali se encontram investidos.

\section{O CONTEMPORÂNEO DA BASE}

Para evitar a repetição, não elencarei pontos críticos sobre a Base, já discutidos pela ANPED (Associação Nacional de Pós-Graduação em Educação), pela ABRAPEC (Associação Brasileira de Pesquisa em Ciências e pela $\mathrm{ABdC}$ (Associação Brasileira de Currículo) (ANPED, 2015) - embora eles sejam inspiradores deste texto. Após, seguirei uma orientação genealógica, no sentido de buscar dar o que pensar, filosoficamente, sobre as palavras e os atos, por meio dos quais criamos 
essa entidade quádrupla, denominada "Base Nacional Comum Curricular". Concluirei pela indicação de 16 problematizações à BNCC, que foram sendo pensadas e coletadas, junto a alunos e colegas professores da Faculdade de Educação da Universidade Federal do Rio Grande do Sul e de diversas instituições de ensino.

Quando o então Ministro da Educação, Renato Janine Ribeiro (BASE, 2015, p. 2), lançou a Base, iniciou sua apresentação com a seguinte frase "A base é a base". Como pretendemos ir além do "é", falamos da Base como de uma coisa-feita, bem nossa, que tem a nossa cara - considerando, antes, que, em nosso entendimento, formular, organizar, estruturar, modelar, montar uma política pública, seja curricular ou de algum outro tipo, parece ser uma das ações mais difíceis do mundo. Neste sentido, a primeira versão da Base (única disponível) é já um resultado de um tipo de tarefa sobre-humana, feita no registro do binômio O-Estado-tem-o-dever-de-educar e O-cidadão-tem-o-direito-à-educação.

Em segundo lugar, sublinhamos o caráter contemporâneo do texto da Base, o seu enclave explícito e assumido neste século XXI; de modo que se trata de um documento curricular, que não poderia ter sido escrito, nem estar aqui, solto no país, oferecendo-se a nossas organizações, leituras, discussões e debates, no século passado, nem mesmo em seu final. Logo, consiste em um texto tributário, em seu pensamento e linguagem, de difíceis lutas e conquistas políticas, além de acirradas disputas intelectuais, feitas especialmente na segunda metade do século XX e consolidadas na práxis educacional da virada do século. Em função disso, a Base Curricular apresenta-se como híbrida, mestiça, ao mesmo tempo, conservando a tradição e a atualizando, dando atenção e abrindo espaço para o que tratávamos, então, como culturas minoritárias e vozes caladas do currículo.

Dessa maneira, é uma Base responsável, ética e politicamente, como se apresenta, desde o Plano Nacional de Educação (Meta 7, 2014), pela "universalização com equidade", pelo "respeito à diversidade" e pela "gestão democrática (da política pública e das instituições de ensino)". Estabelece-se, assim, um documento, que fala o tempo inteiro em "etnia, origem, idade, gênero, condição física ou social, convicções ou credos" (BASE, 2015, p. 7).

Parece-nos, também, como leitores, que, se comparada aos Parâmetros e às Diretrizes, a Base consiste em texto curricular mais ubíquo, mais leve, mais alegre; e, por isto, mais disposto a criar, junto às suas linhas duras, linhas mais flexíveis, moleculares e, até mesmo, linhas de fuga. Por isso, acho que podemos considerá-lo um texto mais corajoso do que os anteriores, que se dispunham, foram tomados ou interpretados, como Currículos Nacionais - se forçarmos a equivalência: o programa da Ratio Studiorum dos Jesuítas de 1599; o texto curricular do início da República até os anos 60; os textos dos anos 80 , sob a influência da Educação Popular ou da Pedagogia Crítico-Social dos Conteúdos; e assim por diante.

\section{A BASE É COISA-FEITA}

De qualquer modo, a Base é gerada, diretamente, no mínimo, por cinco documentos, quais sejam: Constituição Federal (1988); Lei de Diretrizes e Bases da Educação (1996); Diretrizes Nacionais; Parâmetros Curriculares; Plano Nacional de Educação (2014). Assim, as palavras que advêm desses documentos dispõem a sua própria criação, inclusive, como estratégica, em prol de cumprir metas educacionais, levando a educação a integrar e a funcionar de acordo com as metas que ela mesma define - e palavras importam porque são modos de pensar, sentir, avaliar, subjetivar os outros e a nós mesmos.

Caudatária desses textos, o construto Base é usado para referir aquilo que consideramos currículo escolar; de maneira que, nas escolas, seja garantida a igualdade de acesso e legitimada a unidade e a qualidade da ação pedagógica, em meio à diversidade. Logo, os conceitos diversidade e nacional são introduzidos como elementos de um compossível, que articula os currículos de educação infantil, ensino fundamental e ensino médio a uma base nacional comum; mas que deve ser complementada, em cada sistema de ensino e escolas, por uma parte que atenda à diversidade; isto é, que seja diversificada, de acordo com características regionais e locais.

Assim não é previsto que o duplo, constituído por diversidade e por nacional, seja separado em dois blocos distintos, mas que seja, efetivamente, complementar um ao outro. A junção entre a Base e a parte diversificada é que oportunizaria a pretendida formação integral dos estudantes, nos diversos contextos e níveis de ensino.

Além disso, no léxico e no ideário do texto da Base, encontramos outras palavras, expressões, formulações, ideias, espaços, imagens, signos, personagens, desejos, estratégias, dispositivos, que compõem o seu cipoal teorético e práxico, tais como: áreas de conhecimento; noções e conhecimentos essenciais sobre os fenômenos; processos, sistemas e operações; conhecimento, valores e práticas sociais; exercício de cidadania plena e conteúdos complementares; características regionais, culturais, sociais e econômicas; contextualização e paradigma curricular; vida cidadã, ética, saúde e sexualidade; vida familiar e social; meio ambiente, trabalho, ciência e tecnologia; economia, cultura, cultura digital e linguagens; unidade nacional, habilidades essenciais e conhecimentos básicos; conhecimentos contemporâneos; diálogo, planejamento de aulas e trocas de experiências; avaliação dos alunos e identificação de defasagens; 
colaboração com estados e municípios; consulta pública; crítica, sugestões, pessoas físicas, escolas e instituições; rascunho da Base; primeira versão; Portal da Base Nacional Comum Curricular; e assim por diante.

\section{QUAD: O QUARTETO DA BASE}

Tomamos, agora, o bloco BNCC - Base Nacional Comum Curricular -, enquanto composto como um quadrilátero, e apontamos, ali, alguns elementos, que nos parecem habitar esse tablado conceitual-operatório.

1) Aqui, neste QUAD (que não é o Samuel Beckett, mas lembra), encontramos a primeira ideia, que o puxa: a ideia de Base, que nos remete a alicerce, solo, fundamento de alguma estrutura; o qual, epistemologicamente, indica aquilo sobre o qual repousa um conjunto de conhecimentos; no caso, o de um Currículo (escrito com letra maiúscula) que se apresenta, não de qualquer modo, nem com qualquer denominação, mas como Nacional.

Poderíamos, ainda, tomar Base em outra relação, não muito distante dessa acima, mas, talvez, um pouco menos fixada, menos pesada para sustentar ou carregar alguma estrutura. Se a pensarmos etimologicamente, desde o grego Basís, significará andar, andar com as partes mais baixas do corpo, andar com os pés. De todo modo, a Base, advinda de Basís, mesmo que pudesse ser entendida como os pés de quem anda, ainda assim carregaria peso, carregaria a estrutura ou levaria tudo aquilo que contém, isto é, peso. (Podemos pensar, genealogicamente: como será que aconteceu esta decisão de denominar tal documento de Base? Por que não lhe foi atribuído outro nome? Tal como Fundamentos, Princípios ou, simplesmente, Currículo? Quem decidiu? Por que o fez? Com que interesses teóricos, de senso comum ou de política pública?)

2) Em segundo lugar, nesse quarteto, nos deparamos com a operação conceitual e política, que nomeia a Base como Nacional. Ou seja, que lhe atribui uma enorme força agregatória, homogeneizadora, uniformizadora, indiferenciadora; e, a par disso, que lhe atribui a imensa responsabilidade de indicar um grande conjunto, que vira uma qualificação, enquanto derivada de uma entidade configurada, conformada, desenhada, concebida, pensada e sentida como Nação - no caso, a brasileira.

3) Em terceiro, após a formulação da parelha Base Nacional, nos encontramos com a denominação Comum (como um?). Comum que pode aparecer como trivial, vulgar, normal, habitual, corriqueiro, costumeiro, insignificante, ordinário, batido, serôdio, acanhado, caseiro, simples, corrente, usual; mas que também pode ser entendido como consuetudinário, feito em sociedade ou em comunidade. De todo modo, Comum não remete àquilo que é singular, a nenhuma excepcionalidade ou acontecimento; mas àquilo que, para o pensamento, é já sentido comum, tornado bom senso, virado consenso - e que é compartilhado por todos, por muitos, pela maioria, por todo um povo, por todo um país.

4) Ora, a montagem do quadrado não estaria completa sem o Curricular. Eis que um currículo, para nós, que pesquisamos com a filosofia da diferença, é pensado a partir de um desmoronamento da interioridade do pensamento legitimado, por isso, é sempre nômade, plural, informe. Dotado da potência diferencial intrínseca de agir, pode surgir em qualquer ponto e traçar qualquer linha, irrompendo nas águas mansas da sabedoria adquirida, de modo involuntário, incompreensível e inassimilável. Circulando numa atmosfera de errâncias, um currículo tensiona planos homogêneos e medidas avaliativas. Polimorfo e indisciplinado, não pretende tomar nenhum poder e espanta-se com o servilismo dos currículos oficializados, que atendem às exigências de uma ciência régia ou estatal.

Não entendendo como os currículos oficializados podem ser triunfantes e duradouros, um currículo irritase com os seus torpores, conhecimentos estáveis, valores eternos, sujeitos idênticos e essências constantes. Por isso, abre-se para o novo e consolida-o, mediante a construção de adjacências; então, desfaz-se e renuncia a si mesmo, indo embora para outra parte. Mesmo que os seus fluxos sejam canalizados por condutos e diques, precipita-se, torna a jorrar, transborda, flexibilizando as distinções binárias, ternárias e sintéticas, afetando seus pontos heterogêneos, fazendo com que se revezem, ramifiquemse e se encadeiem, para se tornarem outra vez vetores de transformação.

Vivendo às voltas com as forças do Fora, funciona como uma violência que se abate sobre os saberes consolidados, como um estranhamento recíproco entre o pensamento racional e a realidade da vida. Inconstante, versátil, é um currículo que anda de terra em terra e corre mundo, alternando seus pontos, traçando e apagando trajetos, à medida que vão sendo feitos. Por ser amoroso com tudo aquilo que inventa, conjura as cruéis forças econômicas e políticas; as insuportáveis humilhações humanas e os centros de poder, desenrolando seus segmentos e figuras imóveis, e dispersando-os; de modo que voltem a bailar (CORAZZA, 2008).

Ora, como se vê, o quarteto que nos ocupa, formado por Base, por Nacional, por Comum e por Curricular, não é sem eira nem beira, isto é, não é ingênuo, improfícuo e sem consequências epistemológicas, sociais, políticas, subjetivas. Com ele, e a partir dele, trilhamos um solo minado e comprometido por esses mesmos alicerces. E não se trata tão-somente de um modo de falar, de nominar, de denominar um currículo ou suas bases, como se a 
preocupação fosse apenas de ordem linguística. Trata-se de como este bloco, este quadrado, este quadrilátero, assim constituído, nessa ordem, com essas palavras, gerando tal sigla, nos põe a girar em torno desses eixos, criando uma determinada realidade educacional e não outra e produzindo certos efeitos de um real curricular e não outros. (Pensamos, aqui, o que aconteceria se existisse, naturalmente, algo cuja substância fosse curricular; que tivesse uma existência comum; cuja essência fosse nacional; e cujo modo de funcionamento fosse o de uma base.)

\section{AS FIgURAS DA BASE}

No tablado do BCNN (BASE, 2015), movimentam-se as seguintes figuras:

1. Quatro (4) Áreas de Conhecimentos, quais sejam: Linguagens, Matemática, Ciências da Natureza e Ciências Humanas;

2. Cada Área alberga Componentes Curriculares, que variam em sua quantidade e tipo: a) Linguagens tem 4 Componentes - Língua Portuguesa, Língua Estrangeira Moderna, Arte, Educação Física; b) Matemática - de modo não surpreendente, a Matemática só alberga a si própria; c) Ciências da Natureza tem 4 - Ciências, Biologia, Física, Química; d) Ciências Humanas tem 5 Componentes - História, Geografia, Ensino Religioso, Filosofia e Sociologia.

3. Por sua vez, cada Componente está distribuído em cada uma das Etapas da Educação Básica, ora nos 9 anos do Ensino Fundamental, categorizados em Anos Iniciais e Anos Finais, ora nos 3 anos do Ensino Médio; ou em um só dos níveis, que lhe corresponde.

4. Cada Etapa está constituída por meio de Objetivos de Aprendizagem (são 21.973 objetivos!), uns mais específicos do que outros, outros, mais gerais; uns mais práticos, outros mais filosóficos; e assim por diante.

5. A Integração entre os Componentes Curriculares de uma mesma Área do Conhecimento e entre as diferentes Áreas é prevista pelos 5 Temas Integradores, os quais "perpassam objetivos de aprendizagem de diversos componentes curriculares, nas diferentes etapas da educação básica" (BASE, 2015, p. 16), quais sejam: a) Consumo e Educação Financeira; b) Ética, Direitos Humanos e Cidadania; c) Sustentabilidade; d) Tecnologias Digitais; e) Culturas Africanas e Indígenas.

6. Há, ainda "12 Direitos de Aprendizagem e Desenvolvimento", que são figuras dançarinas.

\section{ARTIFÍCIO FABULATóRIo}

Ao ler a Base, podemos pensá-la, também, como algo criado por nós, desde o entendimento de Nietzsche (2001), expresso num artifício fabulatório, presente no texto da juventude (1873), intitulado Verdade e Mentira no Sentido Extramoral. Neste texto inaugural de crítica à filosofia moderna e ao desenvolvimento de temas, ligados à teoria do conhecimento, o que está em questão é, justamente, a verdade, envolvendo, ao mesmo tempo, a ciência e a arte.

Prenunciando a análise genealógica dos seus anos de maturidade, Nietzsche toma o pathos da verdade como ponto de partida, para definir o que é o conhecimento humano, produzido a respeito do mundo. O texto inicia assim:

No desvio de algum rincão do universo inundado pelo fogo de inumeráveis sistemas solares, houve uma vez um planeta no qual os animais inteligentes inventaram o conhecimento. Este foi o minuto mais soberbo e mais mentiroso da história universal, mas foi apenas um minuto. Depois de alguns suspiros da natureza, o planeta congelou-se e os animais inteligentes tiveram de morrer (Nietzsche, 2001, p.7).

Ou seja, a fábula aponta para o aspecto de exceção, frágil e fugidio, vão e arbitrário, que constitui o intelecto humano no seio da natureza. Eternidades passaram sem que esse intelecto existisse; de maneira que, se ele desaparecesse novamente, nada teria acontecido; visto não haver, para tal intelecto, qualquer missão que ultrapasse o quadro de uma vida humana. Ao contrário, sendo humano e finito, o intelecto só é tratado com tanta paixão por seu possuidor e criador, como se fosse o único eixo em torno do qual o mundo gira. Se pudéssemos entender a mosca, afirma Nietzsche, perceberíamos que ela voa no ar, animada por essa mesma paixão, sentindo que o seu voar é o centro do mundo.

Nada há de tão desprezível e insignificante na natureza, que não transborde como um odre, ao menor sopro da força do conhecer; e assim como todo carregador quer também ter o seu admirador, o humano arrogante imagina ter os olhos do universo focalizados, como um telescópio, sobre suas obras e pensamentos. Por isso, Nietzsche admira-se que o intelecto seja responsável por esta situação; justo o intelecto, cuja incumbência é apenas servir como auxiliar dos seres mais desfavorecidos, vulneráveis e efêmeros, que somos nós, a fim que nos mantenhamos vivos, juntos e relativamente seguros.

Dessa maneira, o orgulho, que acompanha a avaliação, ligada ao conhecimento e à percepção, constitui uma espécie de névoa, que cega o nosso olhar e nossos sentidos, lançando uma ilusão sobre o valor da existência. 
Prisioneiros de uma consciência soberba e enganadora, atiramos fora a chave daquilo que nós mesmos criamos, com o qual nos protegemos e ao qual nos submetemos, como se fosse a melhor coisa do mundo: eterna, imutável e além da física.

Desde essa perspectiva nietzschiana, podemos agora indagar: qual seria a origem da nossa crença na verdade da Base? Ora, se o intelecto humano é um órgão dissimulador, humano e finito, que forja imagens luminosas - que lançam um véu sobre o fundo trágico das existências e o abismo inexpugnável do mundo -, o pathos da verdade da Base seria, nada mais nada menos, do que um determinado estado de ânimo; qual seja, aquele produzido pela situação de desvalia, característica da nossa condição humana: ilusória e dotada de um horizonte limitado.

De modo que estaríamos, assim, diante da relatividade do conhecimento e da necessidade de nos precaver, em relação a este pathos, para não nos afastar do mundo real e do tempo presente. Sendo a verdade e a mentira ditadas pelo critério de utilidade, ligado à paz e à conservação do humano, não podemos esquecer que, em primeiro lugar, a verdade da Base Nacional seria tão somente a verdade legitimada, expressa através de palavras consideradas comuns (como uns).

Do mesmo modo que outros espaços e gestos, palavras e imagens, signos e discursos, manifestariam importantes experiências individuais, singulares, próprias a grupos, comunidades e culturas, que complementariam a Base; mas que, dela, estão ausentes. Precisaríamos ter, ainda, prudência, em relação a conceitos, noções e palavras - que são os meios abstratos através dos quais o intelecto humano pretende dizer a verdade das coisas -, visto que são, sempre, metáforas construídas, a partir da identificação do não-idêntico, da igualação do não-igual e da indiferenciação do que é, por natureza, em si mesmo, desde sempre diferença.

Logo, diante da armação humana, do artifício fabulatório, que chamamos Base Nacional Comum Curricular, seríamos, ao mesmo tempo, gênios da sua arquitetura, desde que forjada por nosso intelecto, que portamos, com orgulho e obstinação; e, também, seríamos mestres da dissimulação; pois, para fabricá-la, tivemos, como tarefa, metaforizar o mundo; tratando não apenas de capturar as suas pesadas estratificações; mas, sobretudo, de aparelhar a própria Base - para que, por meio dela, possamos durar, nem que seja, um minuto a mais, sobre a superfície da Terra.

$\mathrm{Ou}$, a Base funcionará como uma "garantia da Verdade", tal como escreveu Althusser (1988, p. 165): “A Verdade só está ali para garantir, em última instância, a ordem estabelecida das coisas e das relações morais e políticas entre os homens".

\section{Problemáticas E QUeSTionamentos}

Como não há outro jeito de permanecer vivos e ativos, e como a Base já tem a sua concretude existencial de coisa-feita, atuando, aqui-e-agora, de alguma maneira, resta-nos ver aquilo que ela produz e aquilo que, com ela, conseguimos fazer, pensar e desejar. Nessa direção, apontamos alguns questionamentos e problemáticas acerca de sua construção textual e material, que foram sendo coletados, bem como que foram sendo pensados, durante o estudo e a preparação desse artigo e de outras intervenções (Corazza, 2015; 2016a; 2016b).

1. Currículo. Em 24 de maio de 1996, durante o segundo ano do primeiro mandato do presidente Fernando Henrique Cardoso (1995-2002), os professores da FACED (1996) expressaram a sua posição sobre os Parâmetros Curriculares Nacionais (após várias reuniões e muitas discussões). Estabelecidas as devidas diferenças político-partidárias, econômicas, sociais, subjetivas e culturais, que produzimos, nesses vinte anos, acredito que alguns argumentos, dentre os sete centrais, mantém a sua atualidade; e que, por isso, ainda nos dão matéria para avaliar a Base.

Considerando que a Base tende a funcionar como um verdadeiro Currículo Nacional, vale indagar (como fizemos com os PCNs) se faz sentido a ideia de ter um currículo deste teor e abrangência; e, ainda, se dele necessitamos e o desejamos. Diante do complexo de fatores econômicos e sociais, responsáveis pela desigualdade e pelo fracasso escolar, criar um diagnóstico ou uma solução (um remédio), como um Currículo Nacional, não seria minimizar fatores relevantes, como: a espúria remuneração do magistério, escolas mal equipadas, prédios deteriorados, má qualidade do material didático, deficitária formação dos professores, etc.?

2. Nacional. Em um mundo dividido e hierarquizado por classe, gênero, etnia, religiosidade, problematizamos a própria concepção de "nacional", desde que, deste modo, essencializamos o que é sujeito a múltiplas interpretações. Como, num país de dimensões transculturais, como o Brasil, podemos nos autorizar a falar em "identidade cultural nacional"; e, desde aí, estabelecer um "padrão curricular comum" (PCNs); criando, agora, uma "Base Nacional Comum"? Nesse jogo básico da Base, como manter as relações entre unidade e singularidade; uniformização e multiplicidade; hegemonização e pluralidade; diversidade e diferenças; inclusão e atendimento às diferenças?

3. Estatal. Ainda junto ao Dossiê de 1996, é possível pensar que, devido ao tipo de texto estatal, formulado e distribuído por um órgão governamental, como o Ministério da Educação - com poder de imposição, sanções, recompensas, concessão ou negação de recursos, 
financiamentos, etc. -; aliado às condições deficitárias e cronologicamente escassas, em que este texto vem sendo posto em circulação, se o "espírito" da Base pode ser, de fato, considerado flexível.

Ou seja, parece difícil que um texto curricular, investido de tal envergadura de Estado e com tais minúcias - embora resultado de muito trabalho, por parte de representativos colegas das várias áreas -, seja percebido, sentido e avaliado, pelos professores das escolas, como não-obrigatório.

É evidente que esse tipo de percepção, normativa e prescritiva, dificulta a dedicação necessária a um amplo debate coletivo, por parte da comunidade educacional, na direção de acrescentar currículos locais aos princípios gerais da Base. Isso a dotaria, de saída, de um alto teor de autoridade, certezas e verdades; em vez do desejado e referido caráter flexível e sujeito a modificações, adaptações e acréscimos, que a discussão pudesse sugerir, seja em seu núcleo comum ou componentes curriculares.

4. Direitos. Consideramos também problemático que o estabelecimento de uma Base Nacional possa ser, em alguma medida, responsável por garantir o "direito à educação", os "doze direitos de aprendizagem" (BASE, 2015, p. 15), ou o "desenvolvimento integral" do aluno (BASE, 2015, p. 11). Isso se, paralelamente à discussão, melhoria e implementação da Base - que é, sem dúvida, vinculada a relações de poder, interesse, regulação e dominação -, não forem melhorados outros fatores, diretamente ligados à qualidade e distribuição justa da educação, como: valorização financeira e social do magistério; distribuição prioritária de recursos; efetiva inclusão, acompanhada da educação necessária aos diversos grupos; adoção de políticas econômicas e sociais; e assim por diante.

5. Trampolim? Mesmo que seja afirmado pelo MEC que a Base não é um Currículo Nacional - mas um referencial para a produção de currículos, como um documento de gestão pública, que fará a gestão dos currículos nas Redes -, pensamos como a Base será significada e usada por nós, educadores? A favor das conquistas que fizemos em todos esses anos? Para o seu retrocesso, raiva atávica ao novo, ou retorno fascista aos neo-arcaísmos? De modo a penalizar ainda mais os já penalizados? Como um trampolim, para saltarmos sobre os interesses hegemônicos? Funcionará para que possamos nos reapropriar das duas maiores responsabilidades éticas de nossa profissão: curricularizar e didatizar, criadoramente? Ou deixaremos que sempre outros - por mais competentes e preparados que sejam - façam o que seria unicamente da alçada de nossa especificidade profissional?

6. Consulta. Pensamos se houve tempo suficiente para realizar um diagnóstico curricular, por parte da
Secretaria de Educação Básica, considerando que: a primeira consulta (restrita) foi iniciada em agosto em agosto de 2014; depois, a segunda etapa da consulta (pública) no site (http://basenacionalcomum.mec.gov.br/) começou dia 26 de setembro de 2015 e foi encerrada em 15 de dezembro do mesmo ano; para, então, reabrir até 15 de março de 2016, já contendo um documento que apropriava os 10.379 .882 contribuições, intitulado "Encaminhamentos para revisão do documento preliminar da BNCC: proposições a partir dos dados da consulta pública".

Além de escasso o tempo de consulta, o tipo de consulta que foi aberta também parece problemático, diante da necessidade de discussão coletiva, de participação ampla, que envolva todos os setores e grupos interessados na educação, secretarias, movimentos, associações, sindicatos, em 27 estados da federação.

Ainda mais: o documento original possui 300 páginas e tanto o acesso quanto a navegação pelo site da Base apresentam-se como difíceis e pesados. Ou seja, estamos diante da necessidade de mobilização da sociedade civil, em pouquíssimo tempo - vejam-se algumas iniciativas de organização, como a da Secretaria de Educação de Santa Catarina -, enquanto a denominada (pelo MEC) "consulta pública", em verdade, apresenta-se mais como uma (simples, básica) enquete de opinião.

Enquete que precisa ser feita acerca de maciços blocos de Objetivos, disposta sob a forma de escolha simples, a qual contém as seguintes alternativas: 1) Concordo fortemente; 2) Concordo; 3) Sem opinião (trata-se, de fato, de uma questão de "opinião"?); 4) Discordo; 5) Discordo fortemente. Cada participante deve responder, obrigatoriamente, a uma alternativa, sem o que não poderá prosseguir. Os critérios disponibilizados são os seguintes: 1) "a linguagem é clara e permite discussão pública"; 2) "as ideias são pertinentes e relevantes para a área ou componente curricular" (qual "linguagem"? quais "ideias", que aparecem após a aplicação dos Filtros?)

Outra questão disse respeito a quem fez e com qual metodologia foram apropriadas essas avaliações, a partir de 15 de dezembro de 2015? Ou seja, acredito que, se queremos um Currículo Comum de Direitos e Deveres de Aprendizagem, temos que ter tempo, garantias de mobilização, muita discussão e espaço para negociações e embates; de modo que tanto o processo como o seu resultado sejam, de fato, comuns e nacionais. (Se isso for possível e se for o que nos interessa.)

7. Disciplina. Da forma como está constituída, parece que a Base incrementa o trabalho didático e curricular elevadamente disciplinarizado, formulado em partes, por especialistas, por etapas (a maioria) - exceção aos Componentes Curriculares Artes e Educação Física (por ciclos). Como ficam as articulações entre as dimensões, 
campos de experiência, componentes, anos? Entre as Áreas? Onde ficam os espaços de manobra para a antiga interdisciplinaridade? E, mais do que ela, para criarmos as contemporâneas transdisciplinaridade, transemiótica, translinguística, transculturalidade?

8. Autonomia. A sensação de leitura da Base leva-nos a pensar se as Diretrizes, por exemplo, não teriam forjado uma situação de maior protagonismo e autoria para os professores. Se a Base, do modo como está expressa e organizada, não levaria os professores, mais uma vez, à posição passiva de consumidores de um currículo feito por outros, em outro tempo e lugar. Em função desse caráter externo, indagamos se a Base pode se tornar, mais uma vez, um dispositivo de poder-saber-subjetivação, utilizado para a culpabilização dos professores; especialmente, diante dos seus correlatos, que são as diferentes formas de meritocracia e as avaliações nacionais, como a Prova Brasil e o ENEM.

9. Desequilíbrio. Existiriam dois campos, dois estratos, no mínimo, que seriam constitutivos da Base que está por vir: um mais forte e organizado, formado pelo Legislativo, pelo MEC e pelos Conselhos Nacional e Estaduais de Educação; o outro mais fraco, formado pelas escolas e pelos professores. Talvez, necessitemos minimizar o desequilíbrio entre as forças e as capacidades organizacionais de cada um desses campos e seus correlatos graus de poder e articulação.

10. Blocos. Mesmo que não seja assumida a distinção entre "conteúdos mínimos" e (a fantasmagórica) "parte diversificada"; e que seja referido pelo MEC que não existem dois blocos distintos, mas complementares; pensamos se não estamos, novamente, diante do nosso velho conhecido duplo. De um lado, como mínimos, viriam as disciplinas nobres, as que valem no ENEM, as autorizadas; e, de outro, viria o resto, o que sobra, o que é perfumaria, o que só se acrescenta de favor, como os "temas transversais", ou "temas integradores", como aquela parte menor - a qual, no caso, corresponderia, justamente, aos currículos locais, grupais, comunitários, regionais.

11. Objetivos. Diante da forma textual da Base, descrita em seus Componentes Curriculares, por meio de "Objetivos de Aprendizagem", consideramos perigosa a possibilidade de, daí, resultar uma espécie de "Taxionomia de Objetivos de Aprendizagem"; uma "Taxionomia de Competências e Habilidades", nas esferas cognitiva, afetiva, psicomotora; ou uma "Taxionomia dos 'Direitos de Aprendizagem' e de 'Desenvolvimento"' (BASE, 2015, p.10).

12. Escolas. Chamamos atenção para os impactos possíveis na escola pública e na escola privada - os quais precisam gerar mecanismos de pesquisas, situados para além das burocracias intelectuais e acadêmicas.
13. Privados. Nessa direção, não há como desvincular a Base da política social e educacional mais ampla. Junto ao Dossiê, segue atual atentarmos para os "interesses dos grupos econômicos e empresariais", "que garantam os interesses do capital nacional e internacional". Ficarmos de olho na distribuição de recursos "a setores específicos dos grupos dominantes: usineiros, grandes proprietários rurais, banqueiros, etc."; e avaliar por que a Base interessa ao grande capital, empenhada em submeter a educação a "mecanismos de mercado e à privatização" (FACED, 1996, p. 240).

Como mostra a colega da Universidade Estadual do Rio de Janeiro, Elizabeth Macedo (2014), em importante artigo, necessitamos verificar a interferência e os interesses de agentes sociais privados, em nossas políticas públicas de educação, visando um maior controle sobre os currículos, como um dobramento contemporâneo de governabilidade. Controle tais como o artigo identifica em instituições financeiras, empresas e fundações, ligadas a conglomerados, como: Itaú [Unibanco], Bradesco, Santander, Gerdau, Natura, Volkswagen, Fundação Victor Civita, Roberto Marinho, Fundação Lemann, CENPEC, Todos pela Educação, Amigos da Escola, entre outros.

14. Alternativos. Sinalizamos, diante da Base, considerada um Currículo Nacional, para o perigo de uma possível colonização e enfraquecimento das concepções mais criadoras e locais de currículo. Nessa direção, lembro um artigo de minha autoria (Corazza, 2001), datado de quinze anos atrás, publicado na Revista Brasileira de Educação, e denominado "Currículos alternativos/oficiais: o(s) risco(s) do hibridismo" (Reunião Anual da ANPED, 2000), em que pesquisei similaridades discursivas entre os PCNs do Ministério da Educação do Brasil, tidos como currículo oficial, e o Movimento Constituinte Escolar do governo petista do Rio Grande do Sul, proposto como um currículo alternativo, progressista, de esquerda.

Refletia sobre o que vinha acontecendo com nossos currículos alternativos críticos, que estavam propondo o mesmo discurso curricular que o Governo Federal. Argumentava que, em função desse hibridismo, precisávamos, outra vez, desfazer o risco de ligação, produzir e praticar currículos que ainda não existiam, para inventar mais uma vez a diferença. (Parece que precisaremos fazer isto, desta vez, e sempre.)

15. Verificação. Penso que, em encontros e reuniões que atravessem as disciplinas e o Ensino-De-AlgumComponente-Curricular, precisamos mapear, numa espécie de cartografia: $1^{\circ}$ ) se o processo de elaboração da Base (que surge fragmentada, muitas vezes) contemplou todas as múltiplas e diversas vozes que têm algo a dizer sobre currículo no pensamento educacional 
contemporâneo (professores de anos iniciais, sindicatos de trabalhadores, movimentos sociais, associações acadêmico-científicas, etc.); 2º) se não privilegiou um número muito reduzido de especialistas, consultores e perspectivas; $3^{\circ}$ ) se discordâncias e diversidades movimentam, saudavelmente, o texto da Base, como todo currículo que se preze; 4o) se sabemos responder, em uma frase, qual perspectiva ou eixo ordenador é o da Base; ou se ela é uma colcha de retalhos, mesmo atual; 5) que tipo de sujeito a Base deseja; $6^{\circ}$ ) quais verdades, valores e crenças ela divulga; 7o) quais relações de poder e formas de saber são as suas preferidas; 8o) de que tipo é e como se configura não só a Formação, mas a Docência em ato dos professores.

16. Questões pipocas. Por último, formulo, rapidamente, algumas questões pipocas.

a) Por que a "Matemática" ficou reinando sozinha, como uma das quatro Áreas de Conhecimento? E, diferentemente da área "Linguagens", por que ela é dita no singular? Afinal, há somente um tipo de Matemática? E a Etnomatemática, que nasceu no Brasil, em suas diversas versões, não caberia aí?

b) Por que a denominação "Cultura" está escrita, durante a maior parte do texto da Base, no singular? Não existe já consenso que temos "culturas" no plural, de vários tipos, como a juvenil, a negra, a indígena, etc.?

c) Entra século e sai século e ainda estamos presos ao Etapismo, a uma cronologia etapista da vida humana e educacional. Consideramos, de fato, que a idade cronológica dos alunos e as etapas de ensino expressam as reais subjetividades emergentes e esgarçadas, os sujeitos desfigurados e os tipos sociais transitórios, em seus anseios e interesses? Temos certeza que a Educação Infantil (da Infância deste século), por exemplo, corresponde ou deve continuar correspondendo, mesmo, aos 4 e 5 anos? (E assim por diante: Ensino Fundamental, 6-14; Ensino Médio, 15-17?)

d) Por que os "Objetivos" são somente "de Aprendizagem" (BASE, 2015, p.15)? Por que a Base não formula "Objetivos de Ensino"? Os campos de Didática e Formação de Professores já não têm acúmulo suficiente para proceder a este dobramento, que enfoque o que os professores fazem, criadoramente, quando ensinam?

e) Por que os "Direitos" são, apenas, "de Aprendizagem e de Desenvolvimento"? Por que não existem "Direitos de Ensino" ou "Direitos de Docência"? Como por exemplo, o Direito à Tradução e à Transcriação?

f) E não parece estranho que, após tantos séculos, ainda situemos a "Aprendizagem" do lado jurídico do "Direito"? E não ao lado da aventura, do enigma, do acontecimento, do prazer ou da beleza?

\section{FORA DAS ILUSÕES}

Para concluir, proponho pensar e sentir a Base Nacional Comum Curricular, como abertura democrática para a formulação de novos problemas antes do que soluções. Como um currículo, que estimule processos de singularização e incorpore zonas de indeterminação; ultrapasse o pathos da verdade, para incluir o acaso e criar inovadores movimentos; diminua o sintoma social das palavras calcadas, sequestre a posição sacrificial dos professores e os disponham em um permanente devir-revolucionário.

Currículo, para além de básico, que leve os professores a falarem, novamente, dos currículos que lhes competem, para se tornarem, outra vez, autores deles, desde o dia-a-dia da sua docência. Currículo que, portanto, caia fora das ilusões de transcendência, seja de ordem nacional, comum, humana, de direito, de base.

Que possamos, desde esse currículo que emergirá da BNCC, voltar a saudar o desejo de educar e nos rejubilar com a vontade de potência dos professores de produzir vida que gera mais vida. Desejo e vontade, que são os únicos elementos da composição curricular e didática, que transcriam as culturas e o processo civilizatório, diferenciando os seus mapas, numa críticaclínica da saúde de pensar, escrever e ler, educar e viver (CORAZZA, 2013).

\section{REFERÊNCIAS}

ALTHUSSER, Louis. O futuro dura muito tempo; seguido de Os fatos: autobiografias. Tradução Rosa Freire d'Aguiar. São Paulo: Companhia das Letras, 1992.

ANPED (Associação Nacional de Pós-Graduação e Pesquisa em Educação), 2015. Base Nacional Comum: currículo para a educação básica em disputa. Disponível em: <http://www. anped.org.br/news/base-nacional-comum-curriculo-para-aeducacao-basica-em-disputa>. Acesso em: 29 abr. 2015.

BASE NACIONAL COMUM CURRICULAR. Ministério da Educação, Brasília, 2015. Disponível em: <http:// basenacionalcomum.mec.gov.br/>. Acesso em: 01 out. 2015.

CORAZZA, Sandra Mara. Base Nacional Comum Curricular: um trampolim, Zero Hora, Porto Alegre, 2016a. Disponível em: <http://zh.clicrbs.com.br/rs/opiniao/noticia/2016/01/ sandra-mara-corazza-base-nacional-comum-curricular-umtrampolim-4947565.html>. Acesso em: 10 jan. 2016.

CORAZZA, Sandra Mara. Currículos alternativos/oficiais: o(s) risco(s) do hibridismo. Revista Brasileira de Educação, Brasília, n. 17, p.100-154, maio-ago. 2001.

CORAZZA, Sandra Mara. Currículos nômades: múltiplos nomes em 51 fragmentos. VII Seminário de Pesquisa em Educação da Região Sul: Pesquisa em Educação e Inserção Social, Universidade do Vale do Itajaí, SC. 23 jun. 2008. Disponível em: <http://www.portalanpedsul.com.br/admin/uploads/2008/ Curriculo_e_Saberes/Mesa_Tematica/12_05_23_Eixo2_mt sandra.pdf $>$. Acesso em: 05 jul. 2008. 
CORAZZA, Sandra Mara. O que se transcria em educação? Porto Alegre: UFRGS; Doisa, 2013.

CORAZZA, Sandra Mara. Prazo para opinar sobre Base Nacional Curricular encerra em março. ADVERSO/ADUFRGS, Porto Alegre, 2016b. Disponível em: <http://www.adufrgs.org.br/ adverso/edicao-no-217novembrodezembro-2015/>. Acesso em: 30 nov. 2015.

FACULDADE DE EDUCAÇÃO DA UFRGS. Dossiê Parâmetros Curriculares Nacionais. Educação \& Realidade - Currículo e Política de Identidade, Porto Alegre, v. 21, n. 1, p. 229-241, jan./jun. 1996.

FREUD, Sigmund. El malestar em la cultura. In: FREUD, Sigmund. Obras completas de Sigmund Freud. Tomo III. Traduccion Luis Lopez-Ballesteros y de Torres. Madrid: Biblioteca Nueva, 1981a, p.3017-3071.

FREUD, Sigmund. El porvenir de uma ilusion. In: FREUD, Sigmund. Obras completas de Sigmund Freud. Tomo III.
Traduccion Luis Lopez-Ballesteros y de Torres. Madrid: Biblioteca Nueva, 1981b. p. 2961-2992.

MACEDO, Elizabeth. Base Nacional Curricular Comum: novas formas de sociabilidade produzindo sentidos para educação. Revista e-Curriculum. São Paulo, v.12, n.3, out./dez.2014, p.1530-1550. Disponível em: <http://revistas.pucsp.br/index. php/curriculum>. Acesso em: 05 out. 2015.

NIETZSCHE, Friedrich. Verdade e mentira no sentido extramoral. Tradução Noéli Correia de Melo Sobrinho. Comum, Rio de Janeiro, v. 6, n. 17, p.5-23, jul./dez. 2001.

RODRIGUEZ, Sergio Aldo; BERLINCK, Manoel Tosta (Orgs.). A psicanálise de sintomas sociais. Tradução Claudia Berliner e Maira Firer Tanis. São Paulo: Escuta, 1988.

Submetido em 07/04/2016

Aprovado em 30/08/2016 